
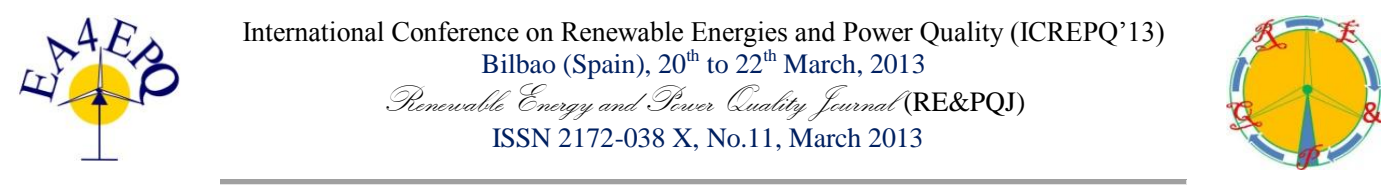

\title{
Modelling solar data: reasons, main methods and applications
}

\author{
M. de Simón-Martín ${ }^{1}$, M. Díez-Mediavilla ${ }^{2}$ and C. Alonso-Tristán ${ }^{2}$ \\ ${ }^{1}$ Department of Electrical Engineering and Systems and Automatics \\ E.I.I.I., León University \\ Campus of Vegazana, 24071 León (Spain) \\ Phone number: +0034 987 291000-5391, e-mail: miguel.simon@unileon.es \\ ${ }^{2}$ Department of Electromechanical Engineering \\ E.P.S., Burgos University \\ Campus of Río Vena, 09001 Burgos (Spain) \\ Phone number: +0034 947 251000, e-mail: mdmr@ubu.es, catristan@ubu.es
}

\begin{abstract}
The main aim of this research work is to analyse the importance of modelling solar data. Should engineers and scientists spend time modelling solar data from other variables or it is a simply waste of time? Which applications truly need a precise forecast of the solar variables? Which spatial and time resolution is needed? In this work we have proposed to analyse these questions and give a brief description of the currently existing methods and the targets demanded by industrial and scientific applications in this field.

In the field of modelling solar data there exist many methods and techniques which cannot be completely described here. The authors just want to analyse the relevance of improving these methods for the development of the solar energy.
\end{abstract}

\section{Key words}

Modelling, measuring, forecasting, irradiance.

\section{Introduction}

Since the ancient Greece, and even before, the Mankind has found innovative ways to use the power of the Sun. Since the last century their main applications have been increased due to the development of efficient technologies that allow the conversion of solar power into electricity or hot water. These solar energy technologies have changed the way that many businesses, industries and even houses produce heat, light, hot water, electricity or cooling [1]. Active solar techniques include the use of photovoltaic panels and solar thermal collectors to harness the energy. Passive solar techniques include the orientation a building to the Sun, the selection of materials with favourable thermal mass or light dispersing properties and the design of spaces that naturally circulate air [2]. Its impact is such that it is highly present on the political agenda in many countries. So, we can conclude that a deep analysis of the solar resources is mandatory for the development of this kind of technologies.
Moreover, solar irradiation on the Earth surface has implications on hydrology, climatology, agriculture and many other human activities.

The solar irradiation that arrives to the external part of the Earth atmosphere has an average value of 1373 $\mathrm{W} / \mathrm{m}^{2}$ and it is almost constant (except it happens any kind of sun storms). However, on the Earth surface, that value decreases to an average of $1000 \mathrm{~W} / \mathrm{m}^{2}$ approximately and it has quite a huge uncertainty due to the geographical coordinates, the meteorological conditions, pollution (which causes diffraction in the atmosphere), shadows from near obstacles, etc. So it is not an easy task to model the irradiation behaviour at ground level. A horizontal solar radiation of Spain can be seen on Figure 1.

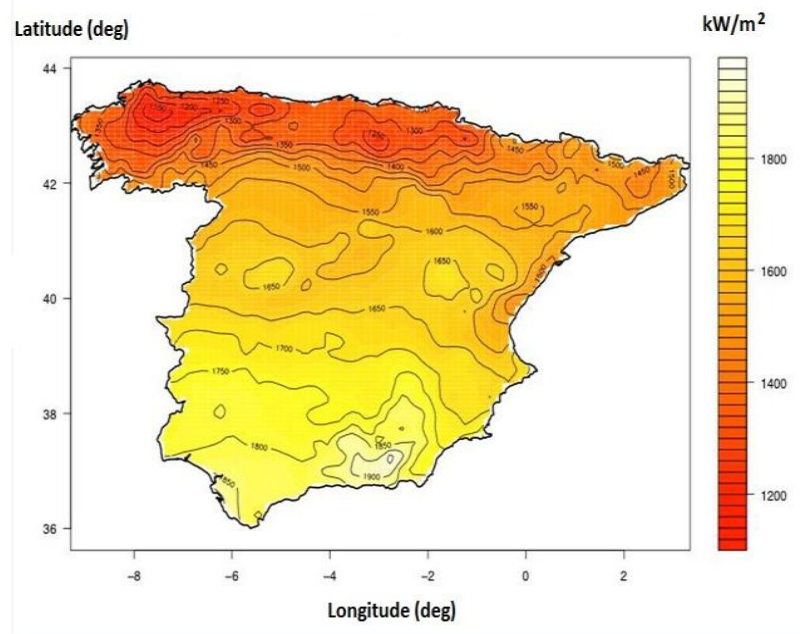

Figure 1. Horizontal radiation map of Spain [3]. 


\section{Measuring solar irradiation}

Some irradiation values can be measured with scientific equipment (pyranometers and pyrheliometers) in some ground stations, but we only dispose of data from very specific places and for a certain period of time [4]. These devices are a special sort of actinometers that can measure broadband solar irradiance on a planar surface from a field of view of 180 degrees (see Figure 2). They offer very high time resolution (typically one minute) so they give best results for different places [5].

Other systems use data collected from meteorological satellites, avoiding in this case problems with the coverage of the measurement instruments with frost, snow or dirt, pollution, failure of the measurement devices itself, etc. Satellites use to measure the radiation coming from the Earth surface reflected from the ground or clouds, so it is mandatory to take also into account the radiation absorbed and reflected by the atmosphere [4].

Geostationary satellites take pictures of the Earth surface every 15 or 30 minutes and on each pixel in the picture (that usually represents a rectangle of few square kilometres) it is estimated the solar radiation of such an area. The space resolution can be increased with Polarorbiting satellites (which fly closer to the Earth surface) but they can only take very few pictures a day of a particular area (they have worse time resolution) [6]. Depending on the case study it would be desirable one kind of satellites or the other one.

Furthermore, satellite methods have special problems with snow on the ground (due to it looks like clouds in satellite images), strong varying altitude areas like mountains and at high latitudes in winter when the sun is very low.

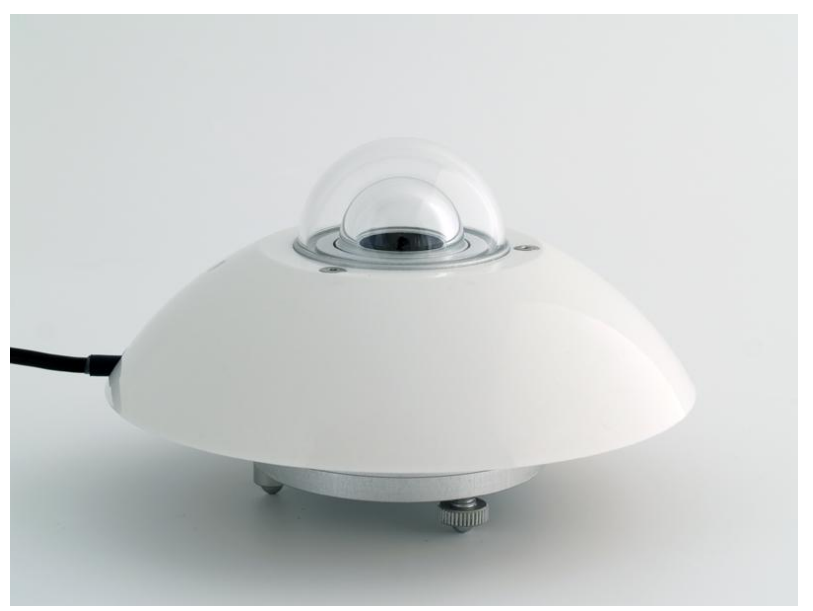

Figure 2. Model of solar irradiation sensor [5].

Whatever the measuring method it can be concluded that we do not dispose of direct measurements on every place at any time and we need to estimate the irradiation values from measurements made nearby. Accurate solar models are mandatory for many applications including forecasting.

On the other hand, measuring solar irradiation is complex, requires expensive specific devices and there are a large number of areas, particularly on developing countries, where measurements are not available or only for short periods of time. In these cases, calculating monthly average daily radiation from other meteorological variables (such as solar hours, temperature or humidity) has a particular interest.

\section{Modelling solar data}

Many different models have been suggested to predict solar radiation [7], [8]. We classify these models in two main groups according to their main aim:

1. Models for predicting irradiation from other climate variables. In this group one can include the following main techniques [9], [10]:
a) Linear models.
b) Non-linear models.
c) Unrestricted models.
d) Polygonal models.
e) Triple estimation models.
f) Fuzzy-genetic models.
g) Neural Network models.

2. Models for space interpolation. In this group it can be included three main techniques:
a) Linear interpolation models.
b) Non-linear interpolation models.
c) Fuzzy-genetic models and Neural Networks.

The mentioned above models can be more or less complex and use different sort of input variables (see Table 1) [10]. The adaptation and reliability of these inputs to the case study allow us to achieve better or worse predictions.

Table 1. Input parameters in solar models*.

\begin{tabular}{|c|c|}
\hline Input type & Parameters \\
\hline Astronomic factors & $\begin{array}{l}\text { Year, month, day, UTC } \\
\text { hour, declination, zenith, } \\
\text { solar constant, extra- } \\
\text { terrestrial irradiation, air } \\
\text { mass. }\end{array}$ \\
\hline Geographic factors & $\begin{array}{l}\text { Latitude, longitude, height } \\
\text { above the sea level, } \\
\text { albedo. }\end{array}$ \\
\hline $\begin{array}{l}\text { Meteorological surface } \\
\text { factors }\end{array}$ & $\begin{array}{l}\text { Air pressure, air } \\
\text { temperature (dry bulb), } \\
\text { relative humidity, wind } \\
\text { speed. }\end{array}$ \\
\hline $\begin{array}{l}\text { Not-integral column } \\
\text { meteorological factors }\end{array}$ & $\begin{array}{l}\text { Ozone level, } \mathrm{NO}_{2} \text { level, } \\
\text { precipitate water. }\end{array}$ \\
\hline Atmosphere turbidity & $\begin{array}{l}\text { Angstrom wave length } \\
\text { exponent, Angstrom } \\
\text { turbidity, aerosol single- } \\
\text { scattering albedo, Linke } \\
\text { turbidity, aerosol optic } \\
\text { depth, visibility. }\end{array}$ \\
\hline
\end{tabular}

* Not all the models use all the input parameters. 


\subsection{Linear models}

Linear models are based on the original Angstrom-Prescott equation:

$$
\left(\frac{H}{H_{0}}\right)=a+b \cdot\left(\frac{S}{S_{0}}\right)
$$

where $H$ is the mean global daily irradiation on an horizontal surface, $H_{0}$ is the mean global extra-terrestrial irradiation, $S$ is the real monthly solar hours, $S_{0}$ is the total theoretical monthly solar hours and $a$ and $b$ are constants related with the studied location.

Although $a$ and $b$ have a physical meaning in terms of clearly and cloudy sky, it is important to notice that:

$$
a+b \neq 1
$$

\subsection{Non-linear models}

This kind of models use non-linear equations for forecasting the global irradiation due to the constants $a$ and $b$ from the original Angstrom-Prescott constants depend on the relation $S / S_{0}$ :

$$
\left(\frac{H}{H_{0}}\right)=a_{0}+a_{1} \cdot\left(\frac{S}{S_{0}}\right)+a_{2} \cdot\left(\frac{S}{S_{0}}\right)^{2}+\ldots+a_{n} \cdot\left(\frac{S}{S_{0}}\right)^{n}
$$

\subsection{Unrestricted models}

The unrestricted model has been developed by Sen in [11]. This author notices that irradiation data not always set the conditions for applying the linear regression. Thus it is more accurate to use the following expressions:

$$
\begin{aligned}
\overline{\left(\frac{H}{H_{0}}\right)} & =a^{\prime}+b^{\prime} \cdot \overline{\left(\frac{S}{S_{0}}\right)} \\
s d \overline{\left(\frac{H}{H_{0}}\right)} & =b^{\prime 2} \cdot s d \overline{\left(\frac{S}{S_{0}}\right)}
\end{aligned}
$$

where $s d$ means the standard deviation.

\subsection{Polygonal models}

Polygonal models use linear regression applied to intervals along the year to take into account the seasonally variations in the solar parameters [12].

\subsection{Triple estimation models}

These models obtain level maps that represent the relationship between two climatic parameters with the solar irradiation and not only the solar hours. The second climatic parameter can be the relative humidity, the environment temperature or the atmospheric pressure.

\subsection{Fuzzy-genetic models}

Fuzzy-genetic models work in the way that through fuzzy techniques we can make groups with the solar data and, applying a genetic algorithm, we can optimize those groups [13].

The main advantage of this sort of models is that we do not need any mathematical expression to describe the solar parameters behaviour. On the other hand, we need a great amount of data to achieve an acceptable accuracy.

\subsection{Neural Network models}

Neural Networks allow us to classify data and learn how to process it in the same way as the animals and humans do with knowledge. They use units called neurons and each neuron is connected with the rest and sends an output signal according to its activation function.

\subsection{Linear interpolation models}

The solar irradiation for a specific location is a linear combination of measures from close locations:

$$
S_{e}=\frac{\sum_{i=1}^{n} w_{i} \cdot S_{i}}{\sum_{i=1}^{n} w_{i}}
$$

$S_{e}$ is the estimated value, $n$ is the number of measures, $w_{i}$ is the weight of the measure and $S_{i}$ is the solar measure.

There exist different options for weighting, as for example:

- Inverse distance.

- Inverse square distance.

- Cressman Method (max. influence radius).

- Sasaki and Barnes Method.

- CSV Method.

\subsection{Non-linear interpolation models}

The value for a specific location is a non-linear combination of measures from close locations as follows:

$$
S_{e}=\sqrt[m]{\frac{\sum_{i=1}^{n} w_{i} \cdot S_{i}^{m}}{\sum_{i=1}^{n} w_{i}}}
$$

\subsection{Fuzzy-genetic models and Neural Networks}

They work in the same way as explained in subsection 3.6 for predicting solar radiation from other climate variables. 


\section{Errors, uncertainties and problems}

For calculating the accuracy of each model it can be used two indicators that compare predicted values with measured values in the case study [10]:

1. Mean Bias Error (MBE). It is defined as:

$$
M B E=\frac{1}{\bar{m}}\left(\frac{1}{n} \sum_{i=1}^{n} e_{i}\right)
$$

2. Root Mean Square Error (RMSE). It is defined as:

$$
R M S E=\frac{1}{\bar{m}} \sqrt{\frac{1}{n} \sum_{i=1}^{n} e_{i}^{2}}
$$

where:

$$
\begin{gathered}
\bar{m}=\frac{1}{n} \sum_{i=1}^{n} m_{i} \\
e_{i}=c_{i}-m_{i}
\end{gathered}
$$

where $n$ is the number of compared elements, $c_{i}$ is the predicted value (result from the model) and $m_{i}$ is the measured value.

The lower are the MBE and the RMSE values the better is the analysed model. In general it is accepted that a model has an accurate behaviour when:

$$
a b s(M B E) \leq 10 \% \quad \text { or } / \text { and } \quad R M S E \leq 20 \%
$$

It also should be noticed that the most part of the models use site specific and/or dependent on the averaging period considered coefficients. This fact makes the model only able to be applied on certain localities of similar climate and for a specific period. In other way results cannot be compared. Some authors like Hay have developed global models with no dependence coefficients by studying multiple-reflection influence, but those methods require cloud albedo and surface data [14].

Furthermore, other authors like Suehrcke claim that the global radiation and the sunshine duration has an approximately quadratic relationship and thus linear models are wrong [15].

\section{Main applications}

Nowadays, the climate change, the security of energy supply for all the industrial process, the dependence of electronic devices and the economic recession have targeted the energy sector in one of the most critical. In this particular case, renewable energy-systems not depending on fossil-fuels can establish the difference between a successful society and others. Therefore, studying the solar potential as a renewable resource has become a key area of interest within energy planning.

Furthermore, the currently implementation of Smart Grids and Smart Cities as a future trend of energy generation, distribution and consuming model has made the prediction of energy production mandatory. An example of a Smart Grid scheme is shown in Figure 3.

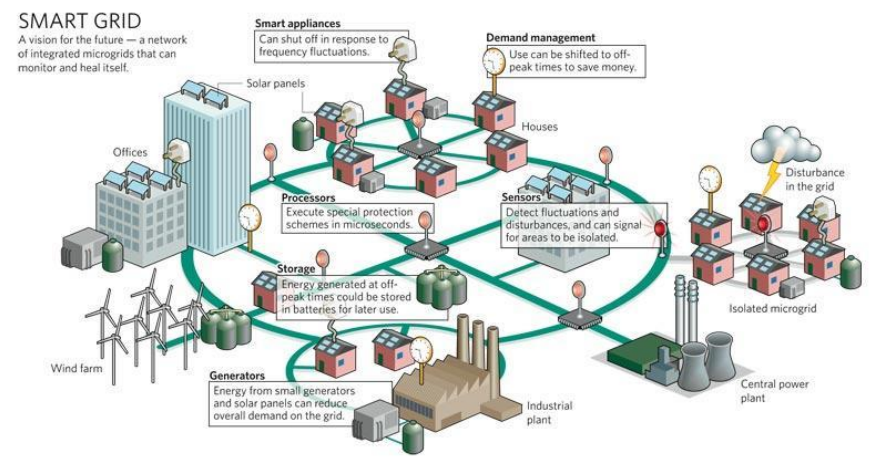

Figure 3. Example of a Smart Grid scheme [16]

In no-energy related fields, solar forecasting is also crucial, as for example for planning crops campaigns, bioclimatic architecture designs [17], wind predictions at certain areas (sun beams heat the air mass heterogeneously), optimal electrical consumption at commercial buildings [18], etc.

The required accuracy depends on the specific application. For example, yearly energy planning of a stand-alone PV plant requires a spatial resolution of few kilometres, and time resolution of days, or even months, is enough. On the other hand, a BIPV application (Building Integrated Photovoltaic) would require a spatial resolution of few metres and a time resolution of hours. It also would be desirable to know the global irradiation on vertical planes with different orientations. Those data will help to design an efficient energy policy.

\section{Conclusions}

It has been widely observed the relevance and need of accurate solar modelling in many fields, focusing in energy planning. There is no doubt that an accurate model for solar prediction allows us to improve our energy systems designs.

Solar data can be modelled in order to estimate solar radiation from other climate variables and time prediction or, on the other hand, it can be modelled for space interpolation. Many models exist with different input parameters and accuracy values.

\section{Acknowledgement}

This research received economic support from the Spanish Government (grant ENE2011-27511) and the Department of Culture and Education of the Regional Government of Castilla y León (grant BU358A12-2). 


\section{References}

[1] M. De Carli and M. Tonon, "Effect of modelling solar radiation on the cooling performance of radiant floors," Solar Energy, vol. 85, pp. 689-712, 2011.

[2] C. Demain, M. Journée, and C. Bertrand, "Evaluation of different models to estimate the global solar radiation on inclined surfaces," Renewable Energy, vol. 50, pp. 710-721, 2013.

[3] O. Perpiñán, Grandes Centrales Fotovoltaicas: Producción, Seguimiento y Ciclo de Vida. 2008.

[4] "PVGIS solar radiation databases." [Online]. Available: http://re.jrc.ec.europa.eu/pvgis/apps4/databasehelp_en.html. [Accessed: 29Dec-2012].

[5] "Pyranometer," Wikipedia, the free encyclopedia. 22-Dec-2012.

[6] T. Huld, R. Müller, and A. Gambardella, "A new solar radiation database for estimating PV performance in Europe and Africa," Solar Energy, vol. 86, pp. 1803-1815, 2012.

[7] T. Khatib, A. Mohamed, and K. Sopian, "A review of solar energy modeling techniques," Renewable and Sustainable Energy Reviews, vol. 16, pp. 2864-2869, 2012

[8] R. Yacef, M. Benghanem, and A. Mellit, "Prediction of daily global solar irradiation data using Bayesian neural network: A comparative study," Renewable Energy, vol. 48, pp. 146-154, 2012.

[9] Z. Sen, "Solar energy in progress and future research trends," Progress in Energy and Combustion Science, vol. 30, no. 4, pp. 367-416, 2004

[10] V. Badescu, C. A. Gueymard, S. Cheval, C. Oprea, M. Baciu, A. Dumitrescu, F. Iacobescu, I. Milos, and C. Rada, "Computing global and diffuse solar hourly irradiation on clear sky. Review and testing of 54 models," Renewable and Sustainable Energy Reviews, vol. 16, no. 3, pp. 1636-1656, 2012

[11] Z. Sen, "Angström equation parameter estimation by unrestricted method," Solar Energy, vol. 71, no. 2, pp. 95-107, 2001.

[12] Z. Sen and A. D. Åžahin, "Solar irradiation polygon concept and application in Turkey," Solar Energy, vol. 68, no. 1, pp. 57-68, 2000.

[13] Z. Sen, "Fuzzy algorithm for estimation of solar irradiation from sunshine duration," Solar Energy, vol. 63, no. 1, pp. 39-49, 1998.

[14] J. E. Hay, "Calculation of monthly mean solar radiation for horizontal and inclined surfaces," Solar Energy, vol. 23, no. 4, pp. 301-307, 1979.

[15] H. Suehrcke, "On the relationship between duration of sunshine and solar radiation on the earth's surface: Angstrom's equation revisited," Solar Energy, vol. 68, no. 5, pp. 417-425, 2000.

[16] "What is the Smart Grid? - Energy Informative," Energy Informative. [Online]. Available: http://energyinformative.org/what-is-the-smart-grid/. [Accessed: 30-Dec-2012]

[17] E. Giancola, C. Sanjuan, E. Blanco, and M. R. Heras, "Experimenta assessment and modelling of the performance of an open joint ventilated façade during actual operating conditions in Mediterranean climate," Energy and Buildings, vol. 54, no. 0, pp. 363-375, Nov. 2012.

[18] C. Tíba and S. S. Leal, "Measuring and modelling luminance in the semi-arid Northeast of Brazil," Renewable Energy, vol. 48, pp. 464-472, 2012. 